\title{
La dignificación de la política según Monseñor Romero
}

\author{
Carlos ayala Ramirez \\ YSUCA \\ $U C A$, San Salvador
}

RESUMEN: El pensamiento de Monseñor Romero deja muchas enseñanzas para bacer de la politica una actividad éticamente digna. La política, llamada a actuar en el ámbito de lo público, debe ser comprendida, al igual que lo bizo Monseñor Romero en su práctica, como una comunicación de la verdad, lucha por el bien común y defensa de la dignidad bumana.

ABSTRACT: There are many lessons in Monsignor Oscar Romero's thought to dignify politics. Politics, which are intended to act in the public sphere, must be understood, as Monsignor Romero did in his practice, as a communication of truth, a struggle for the common good and a defence of human dignity.

La confianza en la política, en los partidos y en las instituciones llamadas democráticas, es, por lo general, muy baja en sociedades como la nuestra. La crisis de la política suele expresarse en la ruptura que existe entre los problemas que la ciudadanía reclama resolver (pobreza, inequidad, violencia, alto costo de la vida, etc.) y la capacidad que aquélla (la política) tiene para enfrentarlos. Tan grave es esta crisis que a la mayoría de la 
población centroamericana (58\%) no le importaría tener un gobiemo no democrático, mientras éste resuelva sus problemas socio-económicos (Latinobarómetro 2004). Eso explica en buena medida varias actitudes ciudadanas entorno a la política: abstención en las elecciones, rechazo a los políticos tradicionales, concebir la política como algo "sucio", negarse a tener alguna relación con la vida política, refugiarse en sus preocupaciones privadas.

Sin embargo, es indiscutible que la política se hace presente en toda nuestra vida ("todo es político aunque lo político no lo es todo"), que los problemas sociales no pueden resolverse debidamente limitándonos al ámbito individual, que la política puede cumplir una función en beneficio de la sociedad considerada como un todo. ¿Qué debe hacerse para que la política retome las aspiraciones ciudadanas más urgentes e importantes? ¿Es posible cambiar el sentido de la política vigente? ¿Cómo recuperar la ética en la política? En Monseñor Romero encontramos una práctica que bien puede ayudarnos a encontrar el camino de la dignificación de la política. Él dignificó la política comunicando verdad, luchando por la justicia, promoviendo el bien común, defendiendo los derechos humanos de los pobres. Él fue coherente con esos valores hasta la muerte. Y lo hizo, no por hacer carrera política, sino como un servicio, como una vocación motivada por el sufrimiento que desencadenaba la represión y la injusticia social sobre las mayorías del país.

\section{La política de la lucha por el bien común}

Digamos, de entrada, que el poder político existe en función de una sociedad y no por sí mismo. Su fuente es la sociedad, pero la sociedad considerada en su totalidad, no en función de una de sus partes y menos, si esa parte es minoritaria, hegemónica y excluyente. Cuando el poder se usa para potenciar el poder de todos, tenemos un poder que sirve a la sociedad en lugar de servirse de la sociedad. A esto llamó Monseñor Romero la "gran política".

Esta es la gran política de la Iglesia: el bien común. Y tiene el derecho, por su función moral en el mundo, de denunciar los abusos de la política y de decir al poderoso que no es Dios, que si algo tiene para mandar es porque Dios le ha permitido $y$, por tanto, tiene que medir sus leyes, sus actuaciones, conforme a la ley del Señor. Pero que ningún poderoso, como los primeros cristianos lo decían a sus césares, a sus emperadores: no era lícito 
quemar incienso ante ellos porque no eran dioses; y que, entonces, era obligación del cristiano, del predicador, del sacerdote, obedecer a Dios antes que a los hombres y no dejarse encadenar por condiciones que le ponga la autoridad civil. (Homilía del 31 de julio de 1977).

El criterio de legitimidad, entonces, es la salvaguarda del bien común como condición para garantizar el bien de cada uno. El bien común o interés general es aquel conjunto de bienes que van, desde los recursos naturales (derecho al agua, al aire puro, a las reservas ecológicas), pasando por los estrictamente socio-económicos ( trabajo, alimentación, salud, educación), hasta llegar a los de carácter ético político (justicia, verdad, libertad). Estos bienes - necesarios para posibilitar una vida digna - tienen que ser accesibles al mayor número de personas (naturaleza común del bien) y tienen que contar con una serie de estructuras e instituciones que posibiliten su efectiva distribución (justicia estructural del bien).

Asimismo, el bien común es una limitación del poder, que no ha de usarse para la arbitrariedad, ni para proteger los intereses de quienes se han apropiado injustamente de lo que corresponde al conjunto de la sociedad. Monseñor Romero lo formulaba con estas palabras:

Hacer lo que Dios quiere es convertirse, hacer mi capricho es pervertirme. ¿Qué quiere Dios con el poder político, por ejemplo, en un país? Quiere que esas fuerzas unan moralmente, por una ley sana, las voluntades de todos los ciudadanos al bien común; pero Dios no quiere que se use el poder para atropellar, para golpear hombres, para golpear ciudades, pueblos. Eso es perversión. ¿Qué quiere Dios del capital? (...) Que se convierta, quiere decir que sepa darle a las cosas creadas por Dios, el destino que Dios le dio a las cosas, que son siempre de Dios, el bienestar de todos, el compartir con todos la felicidad (Homilía del 21 de agosto de 1977).

\section{La política de la lucha contra el mal común}

El Informe sobre Desarrollo Humano 2005 del PNUD, sostiene que en medio de una economía mundial cada vez más próspera, la pobreza y la desigualdad siguen siendo un mal social que flagela a la comunidad humana, especialmente, en los países pobres. Más de 1000 millones de personas malviven en condiciones de extrema pobreza, más de 10 millones de niños no logran llegar a los cinco años de edad. La brecha en la 
esperanza de vida es una de las desigualdades más fundamentales. Según el Informe, hoy, alguien que vive en Zambia tiene menos probabilidades de llegar a los treinta años que un individuo que nacía en Inglaterra en 1840 .

La tendencia de la desigualdad del ingreso mundial es también obscena: el ingreso total de los 500 individuos más ricos del mundo es superior al ingreso de los 426 millones más pobres. Los 2,500 millones de personas que viven con menos de dos dólares al día (el $40 \%$ de la población mundial), obtiene sólo el $5 \%$ por ciento del ingreso mundial. El 10\% más rico, casi todos ellos habitantes de los países de ingresos altos, consigue el $54 \%$. En una palabra, la pobreza y la desigualdad son un mal común. Mal común, porque afecta a la mayor parte de las personas que habitan el planeta. Mal común, porque cuenta con estructuras políticas, mediáticas y económicas que le dan no solo capacidad de propagarse, sino de institucionalizarse en la mayor parte del mundo. Monseñor Romero, siguiendo la doctrina de la Iglesia en su más auténtica y vigente interpretación la llamó "violencia institucionalizada":

En Medellín, se describió la situación de Latinoamérica y se llegó a decir esta palabra que a muchos escandaliza: en América Latina hay una situación de injusticia. Hay una 'violencia institucionalizada'. No son palabras marxistas, son palabras católicas, son palabras de Evangelio; porque dondequiera que hay una potencia que oprime a los débiles y no los dejar vivir justamente sus derechos, su dignidad humana, alli hay situación de injusticia. Y dice Medellín esta frase lapidaria: si el desarrollo es el nuevo nombre de la paz, los pueblos que viven en subdesarrollo son una provocación continua de violencia (Homilía del 3 de julio de 1977).

La política del bien común —que va más allá de ser una abstracción teórica- pasa por combatir el mal común histórico y por defender a las víctimas de ese mal. Pasa también por desenmascarar las visiones políticas y/o religiosas que pretenden vendernos como un bien (con carácter absoluto) lo que no es más que un desorden injusto productor de víctimas. Así lo denunciaba Monseñor Romero:

iAy de los poderosos cuando no tienen en cuenta el poder de Dios, el único poderoso, cuando se trata de torturar, de matar, de masacrar para que se subyuguen los hombres al poder! iQué tremenda idolatría que le están ofreciendo al dios poder! iTantas vidas, tanta sangre que Dios, el verdadero Dios, el autor de la 
vida de los hombres, se le va a cobrar bien caro a esos idólatras del poder (Homilía del 24 de febrero de 1980).

\section{La política del respeto a la dignidad humana}

La política pragmática afirma que todo tiene un precio: el candidato, el diputado, el partido, el voto, el proyecto de ley o la ley, las promesas electorales, el conocimiento, la voluntad, etc. Por este camino hemos llegado al divorcio de la ética con la política $y$, consecuentemente, a considerar la política como un fin y las personas (es decir, a los ciudadanos) como medios. Sin embargo, la ética de la responsabilidad con respecto a los derechos humanos, el medio ambiente y las generaciones futuras, plantea que el objetivo y criterio que ha de orientar nuestras decisiones políticas, económicas, sociales, etc., es la dignidad humana. Todo ser humano ha de ser tratado humanamente, porque posee una dignidad inviolable. Absolutamente valiosas (fin) sólo son las personas; la política, la economía, el capital, los medios de comunicación, la técnica, la ciencia, etc., sí son medios. Y éstos han de ser valorados en la medida en que sirvan al desarrollo humano. Esta es la visión, precisamente, que encontramos en Monseñor Romero.

A la Iglesia no le interesan los intereses políticos o económicos, sino en cuanto tienen relación con el hombre, para hacerlo más hombre y para no hacerlo idólatra del dinero, idólatra del poder, o desde el poder, hacerlos opresores, o desde el dinero, hacer marginados. Lo que interesa a la Iglesia es que estos bienes que Dios ha puesto en las manos de los hombres - la política, la materia, el dinero, los bienes - sirvan para que el hombre realice su vocación de hijo de Dios, de imagen del Señor (Homilía del 17 de julio de 1977).

La Iglesia no puede dejar de promover al hombre, para decirle: No te duermas, eres hijo de Dios, trabaja tu dignidad, sé artífice de tu propio destino, trabaja en tu propio bien común'. La Iglesia no puede dejar, no puede renunciar a esta misión de promoción que el Evangelio mismo le obliga a predicar. Y los colegios católicos y los centros de juventudes, todo aquello donde la Iglesia tiene que decir su palabra, tiene que promover $y$ tiene que despertar la verdadera conciencia del hombre que ha estado muy marginado y que ha sido cómplice del pecado social (Homilía del 24 de julio de 1977). 


\section{La política de la defensa de los derechos humanos}

La paz es fruto de la justicia y la justicia tiene que ver con el ejercicio efectivo de los derechos humanos. Por eso, para una recta política los derechos humanos —en sus diferentes generaciones- son una cuestión de vida o muerte: luchar por los derechos humanos es luchar por la vida y combatir la muerte. Violar los derechos humanos es promover la muerte y combatir la vida. De ahí la necesidad histórica y ética de asumir este conjunto de derechos como rectores de la conducta pública. De ahí también la necesidad de reclamarlos y exigir al máximo su cumplimiento. Este fue, en gran medida, una de las prioridades del ministerio de Monseñor Romero.

La paz es el producto del orden querido por Dios, pero que los hombres tienen que conquistar como un gran bien en medio de la sociedad: (hay paz) cuando no hay represiones, cuando no hay segregaciones, cuando todos los hombres pueden disfrutar sus derechos legítimos, cuando hay libertad, cuando no hay miedo, cuando no hay pueblos sofocados por las armas, cuando no hay calabozos donde gimen pidiendo su libertad tantos hijos de Dios, donde no hay torturas, donde no hay atropellos a los derechos humanos (Homilía del 3 de julio de 1977).

La Iglesia está empeñada boy (...) de cómo no se puede separar la promoción bumana, el cuidado de los cuerpos, de los derechos bumanos de la tierra, de esta obra de evangelización de la Iglesia; de tal manera que no bay por qué poner una dicotomía entre los derechos de Dios y los derechos del hombre, como si el que babla de los derechos Dios se olvidara de los derechos del hombre o viceversa. Cuando bablamos de los derechos del bombre, estamos pensando en el bombre imagen de Dios, estamos defendiendo a Dios (...) Esto quiere decir la frase de Pablo VI: 'La promoción de todo el hombre', alma y cuerpo, corazón e inteligencia, relaciones sociales; que sintamos la igualdad que Dios ha querido de todos sus bijos; que organicemos un mundo mds conforme a esta promoción integral de todo bombre; que todo bombre sienta la capacidad de desarrollar toda su capacidad, de salir de la enfermedad, de encontrar bospitales donde curarse, de encontrar escuelas para todos los niños, que no se queden analfabetas, de promover, pues, en todos los sentidos el desarrollo bumano integral de todo el bombre (Homilía del 9 de octubre de 1977). 


\section{La política que escucha el clamor de los pobres}

La nota dominante del mundo actual es el descuido, la indiferencia y el abandono con el destino de los pobres. Jon Sobrino describe a los pobres como los carentes y oprimidos, en lo que toca a lo básico de la vida material; los que no tienen palabra ni libertad, es decir, a los que se les ha negado su dignidad; los que no tienen nombre ni fecha en el calendario, es decir, a los que se les niega existencia. En una palabra, la mayoría de seres humanos para quienes el hecho de vivir es una carga muy pesada.

Ignacio Ellacuría planteaba que la recta política, al asumir el clamor de los pobres, está en mejores condiciones para ver la verdad de la realidad y para orientar los cambios que requiere esa realidad. Los pobres nos hacen conocer mejor lo que somos: un mundo injusto $e$ inhumano, porque excluye y margina a las mayorías. Según Monseñor Romero, lo inhumano se exacerba cuando se es sordo a ese clamor o, peor aún, cuando se reprime.

El clamor que clama justicia era el clamor del pueblo en Egipto y la Biblia dice: 'El clamor del pueblo ha llegado hasta mis oídos'. Dios escucha cuando el pueblo clama por más justicia, por más caridad, por más orden, más fraternidad. Y no es, pues, de reprimir todo clamor, sino discernirlo. Los clamores que no merecen ser escuchados sí reprímanse. Son las voces del crimen, de los secuestros, de las infinitas cosas que se han quedado sin castigo. Esas sí, reprímanse donde quieran que se encuentren, aunque sea en el ejército. Los abusos tienen que ser castigados. Por eso, invoco la justicia de nuestra patria para discernir y no para simplemente reprimir sin distinciones. Y lo que es justo, óigase. Óigase el clamor justo que puede ser respondido con justicia, principalmente por quienes tienen en su manos el poder de la política y del dinero (Homilía del 20 de noviembre de 1977).

Pero la realidad de los pobres también nos indica cómo y hacia dónde debe encaminarse la política y la economía para que la vida social tenga viabilidad con dignidad, estabilidad con equidad y sostenibilidad con austeridad. Ellacuría hablaba de la civilización de la pobreza, una civilización que supere los males de la civilización de la riqueza. Monseñor Romero habló de la civilización del amor, cuya concreción histórica debe ser la justicia para el pobre.

La civilización del amor no es un sentimentalismo, es la justicia y la verdad. Una civilización del amor que no exigiera la justicia a 
los hombres, no sería verdadera civilización, no marcaría las verdaderas relaciones de los hombres. Por eso, es una caricatura de amor cuando se quiere apañar con limosnas lo que ya se debe por justicia; apañar con apariencias de beneficencia cuando se está fallando en la justicia social (Homilía del 12 de abril de 1979).

\section{La política de la participación ciudadana}

La consecución del bien común y la erradicación del mal común (objetivos de la recta política) dependen, en gran medida, de la participación ciudadana. Pero ésta para que sea cualificada y tenga real incidencia en el cambio social, requiere la existencia de ciudadanos y ciudadanas críticos, creativos y cuidadores.

Críticos frente a la realidad política vigente que se acredita como democrática y que termina reduciendo la participación ciudadana al ejercicio del voto o de la libre expresión (aunque se vote pero no se elija y aunque no todos tengan igual acceso a los medios de comunicación). Según Monseñor Romero, la necesidad de la actitud crítica viene dada porque hay mucho desconocimiento de la realidad, producto de una actitud superficial $o$ indiferente ante la problemática socio-polírica. Por eso demandaba mayor responsabilidad ciudadana, cuya primera exigencia es estar debidamente situados en la realidad. La educación deberá jugar un papel esencial en este cometido.

Que se capacite a los niños y a los jóvenes a analizar la realidad de su país. Que los prepare par ser agentes de transformaciones, en vez de alienarlos con un amontonamiento de textos y de técnicas que los hacen desconocer la realidad. Así hay muchos técnicos, muchos sabios, muchos profesionales que saben su ciencia, su profesión, pero que son como ángeles, desencarnados de la realidad en que actúan su profesión. Lo primero que debe buscar una educación es encarnar al hombre en la realidad, saberla analizar, ser críticos de su realidad. Una educación que sea educación para una participación política, democrática, consciente. Esto, icuánto bien haría! (Homilía del 30 de abril de 1978).

Hay que ser creativos para poner límites a las desviaciones y perversiones del poder y para cultivar relaciones de poder participativo, solidario y ético: participación ciudadana en la elaboración de presupuestos municipales, en la actividad de la asamblea legislativa, en la defensa del medio ambiente, en la defensa del consumidor, en la democratización del los partidos políticos, etc. Poner a producir la creatividad a favor de la 
justicia, era uno de los desafíos que proponía Monseñor Romero a los ciudadanos y ciudadanas que se mantenían al margen del proceso político.

Hago un llamado al sector no organizado que hasta ahora se ha mantenido al margen de los acontecimientos políticos, pero que está padeciendo sus consecuencias, para que como recomienda Medellín, actúen a favor de la justicia con los medios que disponen y no sigan pasivos por temor a los sacrificios y a los riesgos personales que implica toda acción audaz y verdaderamente eficaz. De lo contrario, serían también responsables de la injusticia y sus funestas consecuencias (Homilía del 20 de enero de 1980).

Debernos ser cuidadores de los comportamientos políticos que tienen que ver con el respeto al bien común: el ejercicio del poder-servicio como instrumento de las transformaciones sociales, el control social de las instancias públicas, la regulación del interés privado en lo que éste tiene de amenaza para el interés general, generación de espacios para los movimientos sociales en pro de la justicia global (que no haya lugar para lo superfluo mientras millones de seres humanos no satisfacen sus necesidades primarias). La necesidad de que haya ciudadanía plena responde a uno de elementos básicos de la democracia radical, esto es, que "política" no es sólo (ni es siempre) lo que hacen los políticos, sino lo que hacen las ciudadanas y ciudadanos y sus organizaciones cuando se ocupan de que la cosa pública, sea lo que debe ser: lugar de justicia, de equidad y de integridad ética. Monseñor Romero planteaba la urgencia de este tipo de ciudadanía en los siguientes términos:

Cada uno de nosotros tiene que ser un devoto enardecido de la justicia, de los derechos humanos, de la libertad, de la igualdad, pero mirándolos a la luz de la fe. No hacer el bien por filantropía. Hay muchas agrupaciones que hacen el bien, pero para salir en el periódico, para que se ponga una placa de un gran bienhechor. Hay muchos que hacen el bien buscando aplausos en la tierra. Lo que busca la Iglesia es llamar a todos a la justicia y al amor fraterno, es el bien de la persona que hace el bien, porque se hace más bien el benefactor que el beneficiado. 'Entonces clamarás al Señor $y$ te responderá; gritarás y te dirá: Aquí estoy'. ¿Qué más queremos hermanos? (Homilía del 5 de febrero de 1978). 


\section{La política como servicio humanizador versus la política como opre- sión deshumanizadora}

Hay una fábula bíblica que distingue muy bien entre quien prefiere servir para que haya vida, aunque no tenga poder, y quien busca el poder para oprimir o depredar la vida de otros (corrupción del poder). La historieta la encontramos en el libro de los Jueces (9,6-15): "En aquellos días, los de Siquén y todos los de El Terraplén se reunieron para proclamar rey a Abimalec, junto a la encina de Siquén. En cuanto se enteró Yotán, fue y, en pie sobre la cumbre del monte Garizín, les gritó a voz en cuello: 'iOídme, vecinos de Siquén, así Dios os escuche! Una vez fueron los árboles a elegirse rey, y dijeron al olivo: Sé nuestro rey. Pero dijo el olivo: ¿Y voy a dejar mi aceite, con el que engordan dioses y hombres, para ir a mecerme sobre los árboles? Entonces dijeron a la higuera: Ven a ser nuestro rey. Pero dijo la higuera: ¿Y voy a dejar mi dulce fruto sabroso, para ir a mecerme sobre los árboles? Entonces dijeron a la vid: Ven a ser nuestro rey. Pero dijo la vid: ¿Y voy a dejar mi mosto, que alegra a dioses y hombres, para ir a mecerme sobre los árboles? Entonces dijeron a la zarza: Ven a ser nuestro rey. Y les dijo la zarza: $\mathrm{Si}$ de veras queréis ungirme rey vuestro, venid a cobijaros bajo mi sombra; y si no, salga fuego de la zarza y devore a los cedros del Líbano".

Un comentario bíblico sobre este texto, sostiene que los tres árboles o arbustos mencionados, son los más comunes y estimados en Palestina. El aceite se usa para honrar a Dios en los sacrificios ( $\operatorname{lv} 6,14)$ y para honrar a los huéspedes (Sal. 23,5). La higuera es estimada por la dulzura de su fruto y el vino no sólo alegra el corazón del hombre, sino también se ofrecía en sacrificio a Dios (Lv. 23,13). La zarza -agrega el comentario- es la más insignificante, la más inútil y la más molesta de todos los arbustos. Su invitación a cobijarse bajo su sombra es una fanfarronada ridícula. Pero cuando, en el colmo de la arrogancia, amenaza con que salga fuego de la zarza y devore los cedros del Líbano, su amenaza es real: un fuego prendido en una mísera zarza puede provocar un incendio que abrase un bosque de cedros (el poder para destruir).

Ahora bien, asumiendo la lección de esta fábula —quien más ambiciona el poder no es el que más quiere servir, sino el que quiere imponer sus intereses particulares (partidarios) sobre los intereses generales-, debemos decir que si queremos contrarrestar este modo de hacer política (política prepotente y excluyente), eso implicará la puesta en práctica de lo que algunos han llamado la debida repolitización, es decir: el ejercicio de la política como servicio y recobrar -entre la ciudadanía - el protagonismo 
en las decisiones que construyen la vida social (encargarse de la realidad política, transformándola). Monseñor Romero formulaba esta necesidad de la siguiente manera:

Hermanos, en nombre de Cristo, ayuden a esclarecer la realidad, busquen soluciones, no evadan su vocación de dirigentes. Sepan que lo que han recibido de Dios, no es para esconderlo en la comodidad de una familia, de un bienestar. Hoy la patria necesita sobre todo la inteligencia de ustedes. A los partidos políticos, a las organizaciones gremiales, cooperativas o populares, el Señor (...) les quiere inspirar la mística de su divina Transfiguración, para transfigurar también, desde la fuerza organizada, no con métodos o místicas ineficaces de violencia, sino con verdadera, auténtica liberación (Homilía del 6 de agosto de 1978).

Urge que las organizaciones populares vayan madurando para que cumplan su misión de llegar a ser intérprete de la voluntad del pueblo. La alta dignidad de nuestro pueblo merece que no se tergiverse su sufrimiento, su opresión... (Homilia del 24 de febrero de 1980). 